\begin{tabular}{lllll}
\hline Motrivivência & Ano XX, & No 30, P. 158-168 Jun./2008 \\
\hline
\end{tabular}

\title{
Atividade Física e Saúde: Uma Experiência Pedagógica orientada pela Pedagogia Histórico Crítica
}

\author{
Physical Activity and Health: One Pedagogic \\ Experience that followed the Historical Critic Pedagogy
}

Leonardo Docena Pina'

\begin{abstract}
Resumo
Este texto apresenta uma experiência desenvolvida nas aulas de educação física com alunos matriculados em um programa de educação de jovens e adultos. Essa experiência partiu do método dialético de construção do conhecimento escolar. A experiência desenvolvida buscou situar o tema "atividade física e saúde" como uma ferramenta cultural para tratar problemas sociais concretos gerados ou agravados pelo capitalismo. Palavras Chaves: Educação Física; Saúde; Pedagogia Histórico-Crítica.
\end{abstract}

\begin{abstract}
This text presents an experience in physical education classes with students enrolled in an education program for youth and adults. This experience is based on dialectical method of construction of school knowledge. The experience presents the theme 'physical activity and health' as a cultural tool to understand social problems generated or exacerbated by capitalism.
\end{abstract}

Keywords: Physical Education; Health; Historical Critic Pedagogy. 


\section{Considerações iniciais}

Este texto apresenta uma experiência vivida nas aulas de educação física com alunos matriculados em um programa de educação de jovens e adultos da rede pública municipal de ensino de Angra dos Reis/RJ. Partindo do método dialético apresentado pela Pedagogia Histórico-Crítica (SAVIANI, 2005; SAVIANI, 2006), buscou-se realizar uma experiência na qual o tema atividade física e saúde fosse assimilado como ferramenta cultural para tratar os problemas sociais concretos gerados ou agravados pelo capitalismo.

A escolha desse tema foi delimitada por dois aspectos principais. O primeiro deles consiste no fato de que um trabalho de introdução à educação física realizado com os alunos demandou a necessidade de abordar essa temática, pois ao refletirmos sobre a importância da educação física na escola, eles demonstraram, como entendimento inicial, a ideia de que essa disciplina é importante para promover a saúde através da prática de atividade física. Naquela ocasião, os alunos reproduziram o discurso dominante: não só afirmaram que "a prática regular e correta de atividade física está diretamente associada à obtenção da saúde", como também mantiveram como lacuna a relação da saúde com os problemas sóciopolíticos atuais.

O segundo aspecto consiste no fato de que o planejamento da educação física da rede municipal de Angra dos Reis estabelece como um dos objetivos a serem atingidos o de "criar uma relação entre saúde e atividade física, de modo a desenvolver hábitos para o bem-estar físico, mental e social". Atribuindo uma visão crítica a esse objetivo e seguindo a necessidade de construir com os alunos um novo entendimento - para além do senso comum - sobre a relação entre saúde e atividade física, foi estabelecida uma unidade didática com o seguinte objetivo geral: "conhecer relações existentes entre exercício físico e saúde, a fim de adquirir uma consciência crítica sobre o tema e assumir um compromisso efetivo com a superação dos problemas sócio-políticos atuais que determinam a obtenção da saúde". Para atingir esse objetivo, buscou-se desenvolver o trabalho em conformidade com os cinco passos metodológicos da pedagogia histórico-crítica, tal como evidenciado a seguir.

\section{Identificação da prática social}

Conforme explica Saviani (2006), o ponto de partida do método pedagógico em questão é a prática social. Essa fase consiste em 
uma primeira leitura da realidade, um contato inicial com o tema a ser estudado, de modo que os alunos sejam mobilizados para o processo de construção do conhecimento, sobretudo através da percepção de que existem relações entre o conteúdo e a vida cotidiana (GASPARIN, 2005).

O trabalho de identificação da prática social pode ser dividido em duas partes. A primeira delas é o anúncio dos conteúdos, que consiste em listar o que será trabalhado e quais os objetivos a serem atingidos. A segunda parte é a vivência cotidiana dos conteúdos, que implica em identificar o que os alunos já sabem e o que eles gostariam de saber mais sobre o assunto que será estudado (GASPARIN, 2005).

Seguindo esse posicionamento, buscou-se, inicialmente, informar os alunos de que trataríamos da temática "atividade física e saúde" a partir de um processo pedagógico pautado no materialismo histórico, o qual tem como finalidade a transformação social. Nessa fase, da prática social inicial, foram apresentados os seguintes tópicos a serem trabalhados: (1) exercício físico: seus benefícios e sua importância; (2) saúde: uma questão social; (3) exercício físico garante saúde? Dentre os objetivos específicos estabelecidos, também apresentados aos alunos, pode-se destacar os seguintes: (a) identificar diferentes formas de exercício físico para apontar quais deles podem ser realizados na própria comunidade; (b) entender o exercício físico como meio que pode trazer benefícios à saúde, a fim de assumir uma postura favorável à correta e adequada prática dessas atividades; (c) entender a saúde como uma questão social, resultado das condições de alimentação, habitação, meio ambiente, trabalho, transporte, acesso aos serviços de saúde, dentre outros, de modo a adotar uma postura favorável à superação dos problemas sociais concretos que determinam a obtenção da saúde; (d) analisar diferentes discursos sobre atividade física e saúde para posicionar-se criticamente diante das concepções que estabelecem uma relação direta entre a prática de exercício físico e a obtenção de saúde.

Na vivência cotidiana dos conteúdos, buscou-se identificar o que os alunos já sabiam sobre o tema. Para tanto, foram levantados questionamentos como "o que vocês já sabem sobre exercício físico?", "ele tem alguma relação com a saúde?". As questões levantadas buscaram direcionar um debate inicial sobre o conteúdo para evidenciar a relação entre o tema a ser estudado e os variados aspectos que compõem a vida cotidiana. Ao identificar o conhecimento dos alunos sobre a temática, buscou-se captar o que 
eles gostariam de saber mais sobre exercício físico e saúde a partir de um trabalho em grupo no qual foram sistematizados seus questionamentos. Os trabalhos formulados serviram de base não só para a discussão inicial sobre o tema como para a construção da fase seguinte, a problematização.

\section{Problematização}

O segundo passo do método dialético de construção do conhecimento escolar é a problematização, fase na qual busca-se "detectar que questões precisam ser resolvidas no âmbito da prática social e, em conseqüência, que conhecimento é necessário dominar" (SAVIANI, 2006, p. 71). A partir dessa afirmação de Saviani, dois importantes aspectos foram salientados por Gasparin (2005), merecendo um devido destaque.

O primeiro deles diz respeito às questões da prática social que devem ser detectadas. $\mathrm{O}$ autor esclarece, com base no próprio Saviani, que o foco deve ser concentrado nas grandes questões que desafiam a sociedade, nos principais problemas que precisam ser resolvidos não só na escola, ou pela escola, mas no âmbito da sociedade. Para isso, afirma que deve ser feita uma seleção do que é fundamental, visto que os principais problemas postos pela prática social nem sempre podem ser tratados na sua totalidade em cada área do conhecimento. O "fundamental", vale dizer, referese aos aspectos relacionados ao conteúdo estabelecido pelo currículo escolar ou aos conhecimentos trabalhados em uma determinada unidade do programa. Com base nesse entendimento, pode-se dizer que a problematização deve selecionar e discutir os problemas que têm origem na prática social, mas, que, ao mesmo tempo, se ligam ao conteúdo a ser trabalhado: trata-se de uma seleção e discussão de grandes questões sociais, porém, inseridas e especificadas no conteúdo da unidade que está sendo estudada (GASPARIN, 2005).

$\mathrm{O}$ segundo aspecto a ser destacado refere-se a qual conhecimento é necessário dominar para resolver os problemas da prática social. Gasparin (2005) explica que, de maneira geral, os conteúdos são, quase sempre, transmitidos aos educandos por uma única dimensão: a conceitual-científica. Em virtude da ênfase geralmente atribuída a essa dimensão do conteúdo, o autor alerta o seguinte: é necessário lembrar, no processo de construção do conhecimento, que a ciência também é um produto social, originada de necessidades históricas, econômicas, políticas, ideológicas, filosóficas, religiosas, 
técnicas, dentre outras. Tendo em vista o fato de que existem múltiplas dimensões que revestem os diferentes conteúdos, faz-se necessário abordar, na construção do conhecimento, não só a dimensão conceitual-científica, mas também suas outras dimensões. A necessidade de transcender a abordagem centrada na dimensão conceitual-científica provém do entendimento de que a análise do real deve considerar suas múltiplas dimensões, visto que a realidade social envolve sempre uma gama de perspectivas, um conjunto de aspectos interdependentes, que devem ser entendidos para a resolução dos problemas postos pela prática social.

Levando em consideração esses aspectos, duas tarefas principais podem ser operacionalizadas na problematização. A primeira delas envolve o questionamento da prática social e do conteúdo escolar. Trata-se de um momento em que são apresentadas e discutidas as razões sociais pelas quais se deve aprender o conteúdo proposto, de modo que os alunos possam entender melhor o que será estudado, identificar os principais problemas postos pela prática social e pelos conteúdos e, ainda, entender a necessidade e/ ou validade do conteúdo curricular proposto para solucionar e/ou entender melhor os problemas da prática social (GASPARIN, 2005).
A segunda tarefa que pode ser realizada na problematização refere-se às dimensões do conteúdo a serem trabalhadas. Em linhas gerais, podese dizer que essa tarefa consiste em definir as dimensões que se deseja estudar. Para tanto, pode-se partir do conteúdo a ser trabalhado, de modo a elaborar questões desafiadoras que expressem dimensões específicas referentes à natureza do conteúdo, como, por exemplo, as dimensões científico-conceituais, sociais, econômicas, culturais, históricas, filosóficas, morais, éticas, estéticas, legais e doutrinárias (GASPARIN, 2005).

Ao realizar uma discussão com os alunos sobre os questionamentos da prática social e do conteúdo escolar selecionado, buscou-se evidenciar, principalmente, aspectos contraditórios/controvertidos que envolvem o tema "atividade física e saúde". Dentre esses aspectos, pode-se destacar, a título de exemplo, aqueles que podem ser expressos pela reflexão realizada sobre as seguintes questões: por que estudar esse conteúdo? Por que nem todas as pessoas fazem exercício físico? Todas as pessoas têm tempo para fazer atividade física? Patrões e empregados têm a mesma oportunidade para realizar atividade física? Por que devemos fazer atividade física? A prática de atividade física garante saúde? 
A transformação do conteúdo e dos desafios da prática social inicial em questões problematizadoras ainda passou por outra fase, referente às dimensões do conteúdo a serem trabalhadas. Nesse momento, buscou-se formular as questões mais adequadas, levando-se em conta os objetivos adotados para essa unidade didática. Dessa forma, chegamos aos seguintes questionamentos, com suas respectivas dimensões:

- Dimensão conceitual/científica: O que é atividade física? Por que devemos fazer atividade física? Quais os principais benefícios da prática correta e adequada de exercícios físicos?

- Dimensão histórica: Quando e por que passaram a difundir a ideia de que a prática de exercício físico garante a manutenção da saúde da população em nosso país?

- Dimensão econômica: Todas as pessoas possuem a mesma oportunidade de realizar atividade física? Por que a atividade física realizada durante a jornada de trabalho não é prazerosa como a realizada nos dias de folga? Se atividade física é tão importante para nossa saúde, por que as academias de ginástica têm acesso privado aos que possuem condição de consumo?

- Dimensão social: Todas as pessoas têm tempo para realizar atividade física? Quais são os principais problemas da comunidade que comprometem nossa saúde?

- Dimensão política: A atuação do governo é importante para manutenção da saúde? Dentre os problemas da comunidade que afetam nossa saúde, quais poderiam ser resolvidos pela atuação dos governantes? Quais poderiam ser resolvidos ou minimizados pela atuação da própria comunidade?

- Dimensão ideológica: Por que é difundida a ideia de que atividade física garante saúde?

\section{Instrumentalização}

De acordo com Gasparin (2005), a instrumentalização é o caminho através do qual o conteúdo sistematizado é posto à disposição dos alunos para que o assimilem, o recriem e, ao incorporá-lo, transformem-no em instrumento cultural para transformação da realidade. Esse terceiro passo do método dialético de construção do conhecimento escolar consiste no momento em que os alunos vão se apropriar das ferramentas culturais necessárias à luta social que travam diariamente para se libertar das condições de opressão em que vivem; ou seja, trata-se da fase na qual ocorre a apropriação 
dos instrumentos teóricos e práticos necessários ao equacionamento dos problemas detectados na prática social (SAVIANI, 2006).

Para garantir a apropriação do conhecimento, as ações desenvolvidas partiram de apresentação das experiências dos alunos sobre o tema, exposição dialogada do professor, pesquisa com os integrantes da comunidade, debate do resultado da pesquisa, visualização e discussão de filmes, dentre outros. Em relação aos recursos materiais, foram utilizados filmes, reportagens, além de fotos de problemas da comunidade, de modo a fornecer os instrumentos necessários para responder, de forma mais elaborada, as questões levantadas na problematização.

\section{Catarse}

De acordo com Saviani (2006), o quarto passo do método dialético de construção do conhecimento escolar é a "catarse", que consiste em um momento de expressão elaborada da nova forma de entendimento da prática social a que se ascendeu. "Trata-se da efetiva incorporação dos instrumentos culturais, transformados agora em elementos ativos de transformação social (SAVIANI, 2006, p. 72). Dito de outra forma, a catarse é a demonstração teórica do ponto de chegada, do nível superior atingido pelos alunos (GASPARIN, 2005).

Nessa fase, foi possível compreender que o trabalho realizado possibilitou aos alunos superar alguns entendimentos sobre atividade física e saúde limitados ao senso comum. Ao comparar o que sabiam no início do processo com o que aprenderam no decorrer da unidade didática trabalhada, os alunos manifestaram uma nova forma de entender a relação entre saúde e atividade física. A compreensão de que a atividade física garante saúde, assim como a idéia de que existe uma relação direta entre prática de exercícios físicos e obtenção de saúde, foi sendo elaborada em um novo patamar, no qual os determinantes sociais, políticos e econômicos passaram a ser levados em consideração. Através da apropriação de novos instrumentos teóricos e práticos, os alunos se tornaram capazes de elaborar uma nova síntese mental sobre o tema. Em geral, essa síntese expressou o entendimento de que a atividade física, se praticada correta e adequadamente, pode oferecer benefícios à saúde, sobretudo na prevenção de algumas doenças. No entanto, enfatizaram que, embora possa trazer benefícios, a atividade física não garante saúde, visto que 
esta é uma questão social e sua obtenção requer reivindicação por acesso à habitação, atendimento médico, transporte e educação de qualidade, por garantia de emprego, condições de trabalho seguras, lazer, saneamento básico, alimentação de qualidade, dentre outros. Também foi destacado que, para evitar maiores movimentos de reivindicação, algumas formulações sobre o tema buscam "mascarar" o fato de que adquirir saúde requer atuação dos governantes.

A expressão prática dessa nova síntese ocorreu a partir de dois trabalhos. O primeiro deles foi a elaboração de um texto que retomava algumas questões apontadas na problematização. O segundo foi a apresentação de trabalho em grupo na forma de cartaz com texto e ilustrações, enfatizando que a obtenção/manutenção da saúde demanda requisitos que vão além da simples prática de atividade física. Buscando divulgar a nova síntese elaborada, os cartazes produzidos evidenciaram, inclusive com fotos, alguns problemas sociais vividos pela comunidade que poderiam comprometer a manutenção da saúde da população local. Dentre os problemas apontados pelos alunos, pode-se destacar, por exemplo, nível de poluição da praia, tratamento da água com baixo padrão de qualidade, esgoto a céu aberto, número insuficiente de médicos no posto de saúde situado na comunidade, demora para atendimento com marcação de consultas nesse posto e desemprego.

\section{Prática social final do conteúdo}

Conforme explica Gasparin (2005), a prática social final é nova maneira de compreender a realidade e de posicionar-se nela: é a manifestação da nova postura prática, da nova atitude, da nova visão do conteúdo no cotidiano. Trata-se, ainda de acordo com o autor, do momento de ação consciente em prol da transformação da realidade, a partir do retorno à prática social, agora entendida de forma mais elaborada.

Para Gasparin (2005), a realização dessa fase com os alunos pode envolver basicamente dois aspectos: manifestação da nova atitude prática e proposta de ação. Seguindo esse entendimento, buscou-se firmar com os alunos novas intenções e predisposições para colocar em prática o novo conhecimento elaborado. Vale dizer que a formulação dessas intenções foi acompanhada pela indicação de propostas de ações, tal como indica o quadro 1. 
Quadro 1: Manifestação da nova atitude prática e propostas de ação dos alunos

\begin{tabular}{|c|c|}
\hline \multicolumn{2}{|c|}{ Intenções e propostas de ação } \\
\hline $\begin{array}{c}\text { Manifestação da } \\
\text { nova atitude prática }\end{array}$ & $\begin{array}{l}\text { Proposta de ação da } \\
\text { nova postura prática }\end{array}$ \\
\hline $\begin{array}{l}\text { 1- } \begin{array}{l}\text { Aprender mais sobre a } \\
\text { relação "saúde e atividade } \\
\text { física" }\end{array} \\
\end{array}$ & $\begin{array}{l}\text { 1- Fazer leituras, assistir a } \\
\text { reportagens sobre o tema. }\end{array}$ \\
\hline $\begin{array}{l}\text { 2- Situar-se criticamente } \\
\text { frente às formulações sobre } \\
\text { atividade física e saúde, } \\
\text { utilizando o conhecimento } \\
\text { adquirido para compreendê- } \\
\text { las criticamente. }\end{array}$ & $\begin{array}{l}\text { 2- Analisar formulações sobre } \\
\text { atividade física e saúde } \\
\text { veiculadas pela mídia. }\end{array}$ \\
\hline $\begin{array}{l}\text { 3- Manifestar uma atitude } \\
\text { favorável à prática de } \\
\text { atividade física e à obtenção } \\
\text { de saúde }\end{array}$ & $\begin{array}{l}\text { 3- } \text { Realizar atividade física } \\
\text { nos momentos de lazer e } \\
\text { reivindicar das autoridades } \\
\text { competentes a erradicação dos } \\
\text { fatores que comprometem a } \\
\text { saúde da comunidade. }\end{array}$ \\
\hline
\end{tabular}

\section{Considerações finais}

Desde o final da década de 1970, com o processo de redemocratização da sociedade brasileira, inúmeros estudos passaram a questionar o papel que vinha sendo assumido pela educação física em nosso país, qual seja, o de compor o projeto do bloco no poder por meio do chamado paradigma da aptidão física. Segundo Soares et al (1992), esse paradigma se apóia nos fundamentos sociológicos, antro- pológicos, filosóficos, psicológicos e, enfaticamente, nos biológicos, para educar os indivíduos em conformidade com as necessidades do modo capitalista de produção da existência humana.

Os crescentes questionamentos que ganharam força na década de 1980 colocaram em crise esse quadro de referências que havia direcionado a educação física por mais de um século. A inflexão na área, configurada como uma crise de legitimidade, abriu um período 
de buscas para se construir a autonomia pedagógica da educação física frente a um quadro histórico de vínculo ao projeto dominante. Nesse processo, em que buscavase superar o paradigma da aptidão física, um importante marco para a educação escolar foi a publicação, na década de 1990, do livro Metodologia do Ensino de Educação Física por um grupo que se autodenominou de Coletivo de Autores (SOARES et al., 1992).

Essa obra apresenta o paradigma da reflexão crítica sobre a cultura corporal como alternativa antagônica ao da aptidão física. Trata-se de uma tendência que, pautada na pedagogia históricocrítica, visa a formação do indivíduo enquanto sujeito histórico, crítico e consciente da realidade social em que vive. Para formar esse tipo de sujeito, o paradigma da reflexão crítica sobre a cultura corporal defende a tematização dos conteúdos de forma crítico-superadora. A tematização proposta por essa tendência abrange a compreensão das relações de interdependência que os diferentes conteúdos da cultura corporal - como jogo, esporte, luta, dança, ginástica - têm com os grandes problemas sócio-políticos atuais, como "ecologia, papéis sexuais, saúde pública, relações de trabalho, preconceitos sociais, raciais, da deficiência, da velhice, distribuição do solo urbano, distribuição de renda, dívida externa e outros" (SOARES et al, 1992, p. 62-63).

Embora a pedagogia crítico-superadora represente uma oposição antagônica ao paradigma da aptidão física, não se pode esquecer que a tentativa de superar esse paradigma ocorreu em um contexto de recomposição capitalista. Dessa forma, o processo de inflexão na área foi mediado, na década de 1990, pela ofensiva ideológica do bloco no poder (NOZAKI, 2004). Dentre as implicações disso, podese citar a debandada de intelectuais marxistas, a rejeição da pedagogia crítico-superadora e a adoção de uma nova tarefa, qual seja, a de "superar" o paradigma da aptidão física por um quadro de referências que se mantenha atrelado aos interesses do bloco no poder. Em virtude disso, tem ganhado força, na área, outras tendências da educação física que reforçam a hegemonia do bloco dirigente dos processos históricos. Essas tendências mantêm, em um novo patamar, a essência do velho paradigma da aptidão física.

Desconsiderando a necessidade de articular os componentes curriculares com a compreensão dos problemas sociais concretos, um entendimento que vem sendo difundido atualmente é o de que a 
educação física teria o objetivo de promover a saúde dos indivíduos, principalmente através do culto à adoção de hábitos saudáveis. Esse entendimento incorpora os fundamentos centrais do paradigma da aptidão física. A implicação ideológica dessa vertente é clara: trata-se de uma tentativa de mascarar o fato de que a saúde é uma questão social e que sua obtenção relaciona-se com acesso à habitação, atendimento médico, transporte e educação de qualidade, garantia de emprego, condições de trabalho seguras, lazer, alimentação de qualidade, dentre outros.

Contrapondo-se a essa vertente, o presente trabalho buscou apresentar uma experiência pedagógica na qual o tema saúde e atividade física é pensado na relação com os processos históricos, de modo a evidenciar as contradições da sociedade capitalista. O processo de construção do conhecimento apresentado seguiu os cinco passos do método dialético de construção do conhecimento. Espera-se que as reflexões desenvolvidas possam contribuir não só para o debate sobre esse método de ensino, como também para sua utilização na educação escolar, de modo a formar sujeitos capazes de compreender a realidade social em que vivem para nela intervir criticamente.

\section{Referências}

GASPARIN, João Luiz. Uma didática para a pedagogia históricocrítica. 3 ed. Campinas, SP: Autores Associados, 2005.

NOZAKI, Hajime Tacheuchi. Educação física e reordenamento do mundo do trabalho: mediações da regulamentação da profissão. Tese (Doutorado em Educação). Niterói: Faculdade de Educação, Universidade Federal Fluminense, 2004.

SAVIANI, Demerval. Pedagogia histórico-crítica: primeiras aproximações. 9 ed. Campinas: Autores Associados, 2005. . Escola e democracia: teorias da educação, curvatura da vara, onze teses sobre a educação política. 38 ed. Campinas: Autores Associados, 2006.

SOARES et al. Metodologia do ensino de educação física. São Paulo: Cortez, 1992.

Recebido: 30/agosto/2009 Aprovado: 15/outubro/2009 